21 Fanucchi, Fábio. "Curso de Direito Tributário Brasileiro". Vol. I e II. $4^{a}$ edição, São Paulo, Editora Resenha Tributária, 1986, p. 341/342

22 Jardim, Eduardo Marcial Ferreira. Obra citada. p. 168,

23 Código Civil: "art. 1.055. A remissão concedida um dos co-devedores extingue a divida na parte ele correspondente; de modo que, ainda reservando o credor a solidariedade contra os outros, já lhes não pode cobrar o débito sem dedução da parte remitida.

24 Carrazza, Roque Antônio. Obra citada, p. 381

Ferreira Filho, Manoel Gonçalves. Comentários a Constituição Brasileira de 1988. São Paulo, Saraiva, 1994, vol. 3, p. 107

26 Bastos, Celso Ribeiro e Martins, Ives Gandra. "Comentários à Constituição do Brasil". São Paulo, Sa ralva, 1990, vol. 6, tomo 1, pp. $211 / 214$.

A dicão de micrompresa enquanto que 0 a contrata de porcentagen do ICMS e o que nos interess é 0 artigo $3^{\circ}$ que singelamente diz o seguinte: "Fica dispensado o pasamento do Imposto sobre a Circulação de Mercadorias e sobre Prestacōes de Servicos de Transporte Interestadual e Intermunicipal de Comunicação - ICMS em relação a operaçós ocorridas até a data da publicação desta Lei, com: - alimentação fornecida em restaurantes, bares. cafés e estabelecimentos similares; II - program para computador ("software"), personalizado ou nầo. Parágrafo única. 0 disposto neste artigo não se aplica ao fornecimento e à distribuição de bebidas nem autoriza a restituição de tributos ja recolhi-

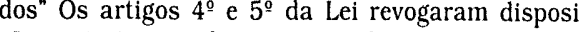
ços anteriores e dispuseram sobre a vigencia imediata da Lei..
Perceba-se a intenção, comum neste tipo de lei, de premiar somente o mau pagador pois aquele que honrou sua obrigacão civica para com o fisco não terá restituição do tributo já recolhido.

28 Processo $\mathrm{n}^{\circ}$ 561/91 da Vara do Anexo Fiscal da Comarca de Sāo Vicente, SP.

29 Agravo de Instrumento $\mathrm{n}^{\mathrm{0}}$ 246.145-2/3 - MV 911 - referente ao processo mencionado na nota anterior

"Convencendo-se, pelas circunstâncias da causa, de que 0 autor e 0 reu se serviram do processo para... conseguir fim proibido por lei, o juiz proferira senlença que obste aos objetluos das partes" (art. C.P.C.

31 Conforme Lei $4.717 / 65$, art. $1^{\circ}$ e RJTJESP 103/ 169

A título de curiosidade trazemos à colação o artigo publicado no Jornal "O Estado de São Paulo" no "Acordos prejudicaram contrucáo de casom", eschAcordos prejudicaram con

to quando diz que "A rede Mcdonte e dela que ele fala anistia fiscal concedida a 300 mil devedores do ICMS entre bares, restaurantes e distribuidores de software." Disse ainda a reportagem que "O governo... deixou de construir cerca de 8 mil casas populares perdoando a divida... "e parcelando outra, somando os casos R $\$ 30$ milhöes". Acrescentou a reporter que o governo "... construiu $88 \mathrm{mil}$ casas populares em cinco anos.. poderia ter feito mais se não perdoasse divida de quem tem dinheiro para pagar segundo o que the disse o presidente do $\mathrm{CDHU}$

Bastos, Celso Ribeiro e Martins, Ives Gandra. Obra citada, p. 212

\title{
As Contribuições Parafiscais no Direito Brasileiro
}

FranZ AUGUST GERNOT LIPPERT

Professor Adjunto da Faculdade de Direito da UFRGS

\section{PLANO DE TRABALHO}

1. Introduçāo: 1.1. Razōes Sociais; 1.2. Razōes Politicas; 1.3. Razōes Orçamentárias; 2. Normas Juridicas Atinen tes a Contribuicōes em Geral: 2.1. Normas Constitucionais; 2.2. Leis Complementares; 2.3. Leis Ordinärias; $\mathbf{3}$. A Natureza Juridica das Contribuicōes Especiais: 3.1. Fato Gerador: 3.1.1. Sujeito Ativo; 3.1.2. Sujeito Passivo; 3.2 Natureza Juridica; 3.3. Situaçāo Atual: 3.4.1. Criação da Contribuição; 3.4.2. Inclusão no Orçamento; 3.4.3. Controle Pelo Tribunal de Contas

\section{PREÂMBULO}

"A parafiscalidade é uma modalidade nova de finanças públicas, embora com antecedentes históricos, própria do Estado intervencionista, visando instituir e utilizar receitas de aplicação especifica, fora do orçamento estatal, à conta de órgãos com finalidades econômicas, de organização profissional, de assistência e previdência sociais, arrecadadas diretamente pelas entidades aplicadoras ou por meios indiretos, inclusive pelas próprias repartições fiscais do Estado.

Sylvio Santos Faria. Aspectos da Parafiscalidade. Livraria Progresso Editora, Salvador, 1.ed., p. 103, 1955.

\section{O SURGIMENTO DAS CONTRIBUIÇÕES ESPECIAIS OU PARAFISCAIS}

Investigando as causas do surgimento das Contribuicões Parafiscais, constata-se serem estas as mais diversas, sendo-lhes, entretanto, comum a necessidade do Estado de obter recursos para o atendimento de suas incumbên-
cias, decorrentes de determinados fatos politicias, decorrentes de determinados fatos politicos, sociais e econ

Caracterizou-se este século: na área social pela tenaz luta da humanidade, objetivando conquistar uma qualidade de vida melhor e, na área politica, por duas guerras mundiais, as quais, se, de um lado, provocaram um progresso enorme em determinadas áreas, especialmente nas areas da ciencias exatas, acarretaram enormes perdas humanas e econômicas, nảo apenas dos paises vencidos, mas também dos paises vencedoręs, com exceção dos Estados Unidos, quanto às perdas materiais.
Tais fatos exigiram do Poder Público, quase a nivel mundial, quanto à obtençảo, adminis tração e aplicação de recursos, ações imediatas, incompativeis com as normas tradicionais da previsão, elaboração e execução orçamentária.

Sendo impossivel, de um lado, atender às inúmeras necessidades sociais, e constatandose, de outro lado, a existência de interesses grupais, a respeito, passou o Poder Público a promover a criação de novos órgãos, relacionados diretamente com aqueles grupos para, aumentar sua eficiência politica e administrativa na solução destes problemas (grupais).

Sendo imprescindivel para o adequado funcionamento dos novos órgãos, também denominados da administração pública indireta, atri buir-lhes os meios financeiros necessários, foram então criadas novas exacões.

Convencionou-se chamá-las de "contribuiçōes parafiscais", "contribuiçōes especiais" ou simplesmente "contribuiçōes", "Sonderabgaben"1 
ou "Parafiskalische Abgaben", "Redevances" ou "Taxes Parafiscales" 2.3

A palavra "parafiscalité", teria sido empregada pela primeira vez em 1947 no "Inventair Schuman"4, objetivando a obtenção de recurso para a recuperação econômica e social da França, após a Segunda Guerra Mundial, através de exações compulsórias marcadas por alguma caracteristicas que as diferenciaram dos tribucaracteristicas
tos clássicos
5.6

A preposição grega "para" pode ser traduzi da como "perto", "pouco distante" ou "ao lado" indicando, conseqüentemente, quanto à matéria ora tratada, uma receita "ao lado do orçamento", "fora do orçamento", "fora do quadro das receitas tributarias tradicionais". "Cinancas parecita" tributarias tradicinais", "lnanças paralelas", finanças, que se situam ao lado das nanças clássicas do Estado.

Emanuelle Morselli ${ }^{7}$ chama atenção basearse a parafiscalidade na distinção das necess dades públicas em fundamentais e complementares, correspondendo as primeiras às finalidades do Estado essencialmente politicas (defesa externa e interna, justiça, etc.) e as segunda às finalidades sociais e econômicas, as quais sobretudo, recentemente, (naquela época) assumiram grandes proporçōes e novas determinações financeiras, destinadas principalmente ao custeio de necessidades de grupos profissionais, econômicos ou sociais.

Os estudiosos da matéria, como Bernardo Ribeiro de Moraes ${ }^{8}$ relatam que o Estado, na mais moderna concepção e como resultado de um conjunto de novos fins e de novas necessidades püblicas, é obrigado a manter dois sistemas de finanças públicas tipicas a saber:

1. o fiscal com seu fim politico e

2. o parafiscal com o seu fim econòmico e social.

Conforme Sylvio Santos Faria ${ }^{9}$, a sede das necessidades econômicas e sociais, que fizeram surgir as contribuiçōes parafiscais, estaria nas categorias e nos grupos sociais, de maneira que o fortalecimento politico das organizacões classistas teve por corolário o desenvolvimento da finança parafiscal.

Para este autor a contribuição constitui "uma modalidade nova de finanças públicas, própria do Estado intervencionista, visando instituir utilizar receitas de aplicação especifica, fora do orçamento estatal, à conta de órgãos com finali- dades econômicas, de organização profissional, de assistência e previdência sociais, arrecadadas diretamente pelas entidades aplicadoras ou por meios indiretos, inclusive pelas próprias repartições fiscais do Estado" (Sylvio Santos Faria) ${ }^{10}$

Para Bernardo Ribeiro de Moraes ${ }^{11}$.

.contribuição especial vem a ser, pois, o tributo cuja obrigação tem por fato gerador uma atividade social do Estado ou de entidade, que tenha a seu cargo o exercicio de funções públicas, efetivas ou potenciais, dirigidas a grupos sociais."

\section{NORMAS JURÍDICAS ATINENTES ÀS}

\section{CONTRIBUIÇÕES SOCIAIS ESPECIAIS OU}

PARAFISCAIS NO DIREITO BRASILEIRO

\section{Normas Constitucionais}

A Constituição Federal atribui no artigo 149 "caput", exclusivamente à Uniāo competência para instituir "Contribuiçoes Sociais" de intervenção no dominio econômico, e de interesse das categorias profissionais ou econômicas, e aos Estados, ao Distrito Federal e aos Municipios a faculdade de instituir exclusivamente contribuicóes cobradas de seus servidores para o custeio de sistemas de previdência.

Estabelece para tanto o artigo 195 da Constituição os aspectos básicos da seguridade social; atribuindo seu custeio direto e indireto à sociedade através de recursos dos Estados, do Distrito Federal, dos Municípios e de Contribuicoes Sociais provenientes dos:

"1.1. empregadores, incidentes sobre a folha de salários,

\section{2. faturamento}

1.3. lucro em geral

2. próprios trabalhadores $\mathrm{e}$ cos."

4.1. Contribuições Sociais: pela legislação desemprego, de seguro contra acidentes, à con-
tribuição ao Serviço Social da Indústria (SESI), em contribuições parafiscais no sentido clás sico (recurso fora do orçamento ao menos da União). Prevê o parágrafo quarto do artigo 195 atinente à seguridade social a criação de outras fontes destinadas à manutenção ou expansão desta, mediante lei complementar, desde que, quanto à tal fonte, não haja cumulatividade $\mathrm{e}$ não tenham as contribuiçōes assim criadas fatos geradores ou base de cálculo próprios dos discriminados na Constituição (art. 154 , I).

\section{Observações}

1. Não existe dispositivo equivalente (ao do parágrafo quarto do art. 195, quanto às contribuiçōes sociais, de intervenção no dominio econômico e de interesse das categorias profissionais ou econômicas do artigo 149

2. 0 prazo de "anterioridade", quanto à cobrança de contribuiçoos destinadas à seguridade social é de apenas 90 (noventa) dias (art. 195 parágrafo $6^{\circ}$ ).

3. Os textos constitucionais mencionados são regrados pelo disposto no artigo 217 do Código Tributário Nacional (C.T.N.), por constituir se o mesmo em Lei Complementar da Constituicão Federal. A sua atual redação decorre: $A$, da Emenda Constitucional no $1 / 1969$, art. 163 , parágrafo único, art. 165, XVI, 166, parágrafo $1^{\circ}$ e da Emenda Constitucional 408/1977, artigo 21 , parágrafo $2^{\circ}$, I, sendo, conseqüentemente, anteriores à atual Constituição Federal.

4. As normas constitucionais e as leis complementares anteriormente mencionadas são complementadas por normas legais ordinárias, e, exemplificativamente, quanto às seguintes contribuiçōes: ordinária atinente à contribuição previdenciária propriamente dita, à contribuição de seguridade social em suas mais diversas variedades, destinada ao financiamento de aposentadorias, de saúde de assistência social, de auxilio de ao Serviço Social do Comércio (SESC), ao Serviço Nacional de Aprendizagem Comercial (SENAC), à Legiāo Brasileira de Assistência (LBA) ao Fundo de Garantia do Tempo de Serviço (FGTS), ao Fundo de Participação do Programa de Integração Social (PIS), ao Fundo de Assisde Integração Social (PIS), ao Fundo de Assis-
tência ao Trabalhador Rural (FUNRURAL) e a

outros;

4.2. Contribuiçōes de Intervenção no Domi-

cos e encargos decorrentes da intervenção da União no dominio econômico "lato sensu", através de diversos financiamentos, como por exemplo, das destinadas à Renovação da Marinha Mercante, incorporadas ao Fundo da Marinha Mercante e as contribuiçōes para o desenvolvimento da indústria cinematográfica brasileira,

4.3. Contribuição de Categorias Profissionais, destinadas ao custeio das atividades de órgãos de classe sindicais, profissionais ou econômicas, incluindo-se neste grupo as contribuições sindicais e as contribuições destinadas à Ordem de Advogados do Brasil e aos Conselhos Regionais de Contabilidade, dos Engenheiros, Arquitetos, Contadores, Agrônomos, etc.

\section{A NATUREZA JURÍDICA DAS CONTRIBUICÕES}

\section{ESPECIAIS OU PARAFISCAIS}

Aliomar Baleeiro ${ }^{12}$ chamou a parafiscalidade de "neologismo afortunado", perguntando se ela contém "algo novo e inconfundivel" como instituto fiscal e categoria ffnanceira, ou, afinal, não passa de uma palavra, sem dúvida cômoda, para distinguir tributo, que se diferencia dos demais, apenas pelo destino especial de sua arrecadação e pela técnica desta". Adotando a segunda alternativa, entendia o autor ser a palavra "parafiscalidade" útil (do ponto de vista exclusivamente signar impostos e taxas que se distinguem das demais pela delegação a um órgão paraestatal a fim de serem aplicados aos fins deste.

Conforme Bernardo Ribeiro de Moraes ${ }^{13}$ caracterizam a contribuição especial ou parafiscal os seguintes elementos:

1) o carăter compulsório da exigência, à semelhança do imposto ou da taxa;

2) a não-integração da respectiva receita no orçamento do Estado;

3) a destinação do produto de sua arrecadação ao custeio de certos grupos, setores ou categorias sociais;

4) a administração de sua receita por entidades descentralizadas e até não-estatais por delegação do Estado.

Alfredo Augusto Becker ${ }^{14}$ entendia que as "contribuiçōes parafiscais" não constituiam uma natureza juridica "sui generis", nem tributo de nio Econômico, destinadas ao custeio de servi- natureza mista, porém, em determinados casos, 
serem simples impostos com destinação determinada e, noutros, verdadeiras taxas, invocando para tanto à fls. 350 de sua obra as opiniōes de brilhantes tributaristas nacionais e estrangeiros.

Entendia o jurista ser assim "porque a destinação do tributo, a sua maior ou menor proporcionalidade (em relação à base de cálculo) e a posição do sujeito passivo em relação à hipótese de incidência do tributo, não exercem qualquer influência sobre a natureza juridica do tributo".

Foi este, também, o entendimento dos autores do Código Tributário Nacional, pois 0 artigo 5 do mesmo não faz qualquer referência a outro tributo, alèm de impostos, taxas e contribuiçōes de melhoria.

Examinando-se este ponto a partir do artigo $3^{\circ}$ do C.T.N. constata-se o seguinte:

"Art. 3: Tributo é toda prestação pecuniária compulsória, em moeda ou cujo valor nela se possa exprimir, que não constitua sanção de ato ilicito instituida em lei e cobrada mediante atividade administrativa plebrada mediante atividad

namente vinculada."
Esta definição não diverge muito da contida no art. 17 do Projeto de Código Tributário Nacional, constante dos "Trabalhos da Comissão Especial do Código Tributário Nacional", doravante apenas "Trabalhos" 15 cujos termos são os seguintes:

"Art. 17: Tributo é toda prestação pecuniária instituida por lei com caráter compulsório pela União, pelos Estados, pelo Distri to Federal ou pelos Municipios, no uso de competência constitucional inerente à sua condiçāo de pessoa juridica de direito público."

Resultou esta definição da alteração do artigo 23 do Anteprojeto do Professor Rubens Gomes de Sousa ${ }^{16}$

Nos seus comentários a este artigo. demonstraram os membros da "Comissão Especial", encarregada da elaboração do Projeto de Código Tributário Nacional, a preocupação de afastar interpretaçōes restritivas do conceito "tributo", fixando para tanto as suas caracteristicas fundamentais quanto a:

1. a origem da receita e sua natureza (pres-

tação pecuniária)
2. o tipo de atuação juridica empregada pelo Estado para sua obtenção (ato legislativo compulsório):

3. o fundamento constitucional do exercicio daquela atuação (competência inerente à personalidade pública do agente), visando distinguir o tributo das receitas patrimoniais, das de caráter contratual e das decorrentes do exercicio pelo Estado de decorrentes do exercicio pelo Estado de atribuições estranhas ao seu caráter
berano, como os preços públicos.

$\mathrm{O}$ art. $5^{\circ}$ do C.T.N., que corresponde integralmente ao artigo 21 do "Projeto", define como "tributos" apenas os impostos, as taxas e as contribuições de melhoria.

Merece destaque neste contexto que Rubens Gomes de Sousa, em 1953, com o conhecimento e a visão que lhe eram peculiares, elaborando o "Anteprojeto do Código Tributário Nacional" já redigiu os artigos 95, 96 e $97^{17}$ (do Anteprojeto), referentes às "Contribuiçōes", conceituando-as como terceira figura tributária genérica, paralelamente aos impostos e às taxas. Esta popar posição, entretanto, nâo foi aceilta pela Comissão $0^{18}$. Mostra Rubens Gomes de Sousa ${ }^{19}$ que nunca se conformou com o entendimento majoritário da Comissão eis que a Constituição Federal então em vigor (a de 1946) no seu artigo 39, I, já previa a existência de "outras rendas", que poderiam ser contribuicões.

Com o advento da Constituição de 1967 e da Emenda Constitucional $n^{0} 1$ de $17 / 10 / 1969$, consignando outras espécies de contribuiçōes, além da contribuição de melhoria, foram aquelas constitucionalizadas. (art. 21, parágrafo $2^{\circ}$, I; art. I63, parâgrafo único; art. 165; XVI e o art. 166, parágrafo $1^{\circ}$ ).

As contribuições sociais, as de intervenção no dominio econômico e de interesse das categorias profissionais previstas no artigo $149 \mathrm{e}$ as da seguridade previstas no artigo 195 da atual Constituição Federal, nem sendo impostos nem taxas, distinguem-se dos primeiros por serem tributos vinculados e das segundas "pela circunstância de que, na contribuição, a atividade estatal que fundamenta o tributo possa ser apenas indiretamente relativa ao sujeito passivo, ao contrário da taxa em que aquela relação entre a atividade estatal e o sujeito passivo é necessariamente direta".
Segundo a lição de Rubens Gomes de Sousa, quanto aos tributos, nos termos constantes do artigo $3^{\circ}$ do C.T.N., existem quatro elementos, que os caracterizam, a saber:

- o tributo é uma prestação compulsória, instituida em lei;

- o tributo é uma prestação pecuniária em moeda ou cujo valor nela se possa exprimir;

- o tributo é uma prestação que não constitui sanção de ato ilicito;

- o tributo é uma prestação "cobrada por atividade administrativa plenamente vinculada".

Explica o mestre ${ }^{20}$ que entre os tributos vinculados, a taxa se caracteriza por ser o seu fato gerador vinculado especificamente a uma atividade estatal (exercicio do poder de policia ou prestação efetiva ou potencial de um serviço) diretamente relativa ao sujeito passivo, devendo esta vinculação estar presente também. na contribuição para constituir-se em tributo vinculado. Mas, então, será necessário para distinguir a contribuição da taxa um outro elemento de especificação, que teria de ser a circunstância de que na contribuicão, a atividade estatal, que fundamenta o tributo "contribuição" possa ser apenas indiretamente relativa ao sujeito passivo, enquanto no caso da taxa esta relação entre a atividade estatal e o contribuinte é necessariamente direta.

Para Bernardo Ribeiro de Moraes a Contribuição Especial è um tributo cuja obrigação tem por fato gerador uma atividade social do Estado ou de entidade que tenha a seu cargo "exercicio de funções pủblicas, efetivas ou potenciais, dirigidas a grupos sociais". Assim sendo, caracteriza-se a contribuição especial por possuir um pressuposto de fato, definido em lei de forma tipica, consistindo numa atividade estatal dirigida à coletividade, que atinge determinado grupo de pessoas, que se beneficiam de certa forma ${ }^{21 "}$

\section{A Competência para Instituição de Tributos}

Como já anteriormente exposto, é da União a competência para instituir e fixar o valor das contribuiçōes especiais, de acordo com o disposto no artigo 149 "caput" da C.F., podendo, entretanto, os Estados, o Distrito Federal e os
Municipios instituir contribuições para o custeio de sistemas de previdência e assistência social de seus servidores.

Observação: Cabe mencionar neste ponto que prazo da "anterioridade", quanto à cobrança de contribuiçōes destinadas à seguridade social é de, apenas, 90 dias (art. 195, parágrafo 6\%) aplicando-se aos demais o principio da anuidade.

\section{O Fato Gerador da Contribuição Especial}

$O$ fato gerador das contribuições especiais em geral é a atividade do Estado ou de seu órgão (com função estatal), visando atingir determinados grupos sociais, beneficiando individual, direta ou indiretamente seus componentes.

São contribuintes das contribuições especiais:

1. as pessoas, que se beneficiam pelas vantagens oferecidas pelo Poder Público

2. pessoas que não se beneficiam pelas vantagens oferecidas, mas que se encontram relacionadas com o suporte fático ou fato gerador da respectiva obrigação tributária como o empregador (art. 195, I), per mitindo o disposto no artigo 195, pará grafo $4^{\circ} \stackrel{0}{ }$, da C.F. instituir por Lei Complementar outras fontes vinculadas à manutenção ou expansão da seguridade social, desde que sejam não-cumulativos e não tenham fato gerador ou base de cálculo próprios dos discriminados na Constituição Federal.

As contribuiçōes especiais integram o orçamento através de dotações globais, de acordo com 0 principio da unidade orçamentária ${ }^{22}$, exceto as receitas dos Estados, do Distrito Federal e dos Municipios destinado à seguridade social

As referidas contribuicōes são fiscalizadas pelo Tribunal de Contas da União, ou órgão de controle da execução orçamentária, quanto à sua administração ${ }^{23}$.

\section{CONCLUSÕES}

1. As Contribuições Especiais ou Parafiscais integram o sistema tributário brasileiro tanto a nivel constitucional como a nivel legal. 
2. A criação de contribuiçōes corresponde a uma tendência generalizada, não apenas decorrente de uma maior facilidade da administracão pública, quanto à obtenção de recursos, mas ção publica, quanto à obtenção de recursos, mas
tambem por atender melhor as exigências da também por atender melhor as exigencias da justiça fiscal, eis que seus contribuintes encon-
tram-se sempre relacionados com o respectivo tram-se sempre relacionados com o respectivo mente com fatos que o compoom.

3. É dominante hoje a opinião que as contribuiçōes parafiscais formam um quarto gênero de tributos, não sendo impostos, nem taxas nem contribuições de melhoria ${ }^{24.25}$

4. As normas juridicas constitucionais e complementares não definem as contribuições especiais ou parafiscais.

5. As contribuições parafiscais são, ainda, pouco usadas com finalidades compensatórias para direcionar atividades econômicas, área onde poderão tornar-se expressivas.

\section{NOTAS DE REFERÊNCIA}

1 Tipke Die Steuerrechtsordnung, Verlag Dr. Otto Sch midt, Köln, 199 v. III, p. 1070-1074.

2 G. Gest/G. Tixier, Manuel de Droit Fiscal. Paris 1986 p. 58-60 "apud" Tipke.

3 Maurice Duverger. "Finances Publiques". Presse Universitaires de France, 1963, pp. 92 a 93 "apud", Gilberto de Ulhoa Canto "Contribuições Sociais Cadernos de Pesquisas Tributárias", v. 17, Editora Resenha Tributária, S.P., 1992. p. 43-44.

4 Robert Schumann ou Schuman, então Ministro das Finanças, e, posteriormente, um dos mais impor tantes artifices da Comunidade Europeía.

A palavra "Parafiscalidade" e a utilização da expressão "contribuição fiscal" deve-se a Emanuelle Mor selli, "Parafiscalidade e Seu Controle" e foi por este Brasileiro de Direito Finnanceiro, Rio de Janeiro. 1.ed., p. 24, 1954

6 "Parafiscalite Taxe e Cotisations percues sous

l'aturité de l'Etat aue e Cotisations perçues sous l'organismeds autonomes" (Petit Larousse Illhs oú. 1985, p. 727).

7 Emanuelle Morselli. "Parafiscalidade e Seu Controle", conferenncias divulgadas pelo Instituto Brasileiro de Direito Financeiro, Rio de Janeiro $1^{\text {a }}$ edicão. 1954. p. 282 .

8 Bernardo Ribeiro de Moraes. Conpêndio de Direito Tributário. 3.ed.. Forensc. p. 623.

9 Aspectos da Parafiscalidade. Livraria Progresso Editora, Salvador, 1.ed., 1955.
10 Op. cit., p. 57.

12 Uma Introduçăo à Ciência das Finanças. Editora Forense, Rio de Janeiro, p. 282, 1978.

13 Op. cit., p. 623.

Teoria Geral do Direito Tributário. Saraiva, São Paulo, p. 349, 1963.

15 Trabalhos, p. 23.

16 Trabalhos, p. 271

Trabalhos, p. 288

“Art. 95: São contribuições os tributos que não ejam especificamente impostos ou taxas.

Paragralo Unico: A competência para institujção de contribuiçoes pertence cumulativamente At, 96: 0 produto da an

Atr bulces te, sob pena de lilegalidade da respectiva cobrança, sido especificamente instituidas. Art. 97: Aplicam-se supletivamente às contribuições as disposições de carâter geral relativas às taxas, contidas neste Código ou na legislação tributária."

18 Trabalhos, n. 36, p. 199:

"O art. 21 do Projeto levantou na Comissão o problema da conceituação das contribuiçōes como uma terceira figura tributária genérica, paralelamente aos impostos e as taxas. Essa orientação, defendida em doutrina pelo autor do Anteprojeto (Revista de Direito Administrativo 26/363) e consignada em seu art. 28, foi atacada pela sugestào 94 , que afirmou nào existirem, alem da contribuição especificamente "de melhoria", qualificativo sempre usado pela Constituição, outros tributos que não $\mathrm{se}$ enquadrem nos conceitos de imposto ou de taxa. A Comissão adotou esse ponto de vista, em que consonância com a sua orientação no tocante aos objetivos sociais autor do Anteprojeto no trabalhado cilado, a utilidade prática de um conceito genètituir regime juridico especial para as exacões de caráter parafiscal: mas exatamente quanto a a esa a Comissão deliberou, em principio, adotar uma atitude de neutralidade juridica (supra: 7)".

19 Rubens Gomes de Sousa. Parecer. A Contribuição da Previdencia Social e os Municipios, p. 55.

20 - Op. cit., pp. 54, 55.

21 Bernardo Ribeiro de Moraes, op. cit., p. 645.

22 Aliomar Baleeiro. Limitacöes Constitucionais ao Po der de Tributo. Forense, Rio de Janeiro, 5 ed, p. 280. 1977.

24 Gilberto de Ulhoa Canto. Contribuições Sociais.

25 Caderno de Pesquisas Tributárias, v. 17, p. 40.

\section{Successor Corporation Liability for Claims Arising Out of Defective Products*}

GILBERTO DEON CORRÊA JUNIOR

Mestre em Direito pela UFRGS.

Mestre em Direito Comparado pela New York University.

Procurador da Fazenda Nacional. Advogado em Porto Alegre.

\section{INTRODUCTION}

Rolim Manufacturing Corporation produces hydraulic shearing machines. One of those shearing machines was sold to Greenberger Brothers Company, Inc. While operating the machine, John McGregor, an employee, was struck by a scrap of metal thrown from it. The piece of metal penetrated one of his eyes and he was blinded. It is incontrovertible that the accident happened because the hydraulic shearing machine was defective. Mr. McGregor can therefore seek recovery for personal injury against Rolim.

Let us assume, for instance, that before the injury Rolim merged with Klinger Shearing Corporation. As a result of the merger, McGregor would be able to sue Klinger because it assumed Rolim's liabilities.

Assume the same facts, but instead of having a merger of the corporations, Klinger just bought Rolim's assets, including all the inventory, trade name, secrets and equipment. Rolim was dissolved five years before the accident and since the transaction Klinger has been manufacturing the same shearing machines, under the same trade name. Does McGregor have a cause of action for personal injuries against Klinger? As we are going to see, the answer to this question can vary depending, on which state's law the court applies.

The general rule in most states is that the corporation which acquires the assets of another corporation does not succeed to the liabil ties of the former ${ }^{1}$ unless:

*Trabalho apresentado no Curso de Mestrado em Direito Comparado da New York University em maio de 1995.
1) there is an express or implied agreement of assumption of the liabilities:

2) the transaction amounts to a consolidation or merger of the purchaser and the seller;

3) the purchaser is a mere continuation of the selling corporation; or

4) the transaction was fraudulent ${ }^{2}$

Some courts add a fifth exception, which is the absence of adequate consideration for the sale or transfer of assets ${ }^{3}$ or the lack of the elements of a purchaser in good faith. ${ }^{4}$

Assuming that the transaction was not fraudulent, Klinger paid adequate consideration and there was no express or implied assumption of liabilities, does McGregor have a cause of action against Klinger?

Exception two, known as de facto merger or consolidation exception, was created to protect the creditors and the minority shareholders in those cases where the companies enter into an agreement that achieves the same results as a merger or consolidation but does not follow the legal steps requirer consolidation. Traditionally, the de facto merger exception requires that the assets be acquired for shares or other securities of the acquiring corporation which are distributed to the company seller shareholders.

The mere continuation exception, on the other hand, causes liability to depend on whether the plaintiff can establish that one or more persons were officers, director, or shareholders of both companies. ${ }^{6}$ 